\title{
Renal Responses to a Series of Handball Games Played in Sub-Saharan Environment by Amateur Division 1 of Female Players
}

\author{
Brigitte Affidéhomé Tonon ${ }^{1}$, Bruno Agboton ${ }^{2,3}$, Jean-Marie Falola ${ }^{1}$, Polycarpe Gouthon ${ }^{1 *}$, \\ Issiako Bio Nigan ${ }^{1}$, Edgard-Marius Ouendo ${ }^{4}$, Hippolyte Agboton ${ }^{5}$, \\ Jacques-Rémy Poortmans ${ }^{6}$ \\ ${ }^{1}$ Laboratory of Physical and Sportive Activities and Motility, National Institute of Youth, \\ Physical Education and Sport, University of Abomey-Calavi, Porto-Novo, Republic of Benin \\ ${ }^{2}$ Department of Nephrology, National Hospital of Cotonou, Cotonou, Republic of Benin \\ ${ }^{3}$ Faculty of Health Science, University of Abomey-Calavi, Cotonou, Republic of Benin \\ ${ }^{4}$ Regional Institute of Public Health/WHO, University of Abomey-Calavi, Ouidah, Republic of Benin \\ ${ }^{5}$ Unity of Formation and Research in Cardiology, Faculty of Health Science, \\ University of Abomey-Calavi, Cotonou, Republic of Benin \\ ${ }^{6}$ Faculty of Motility Sciences, University of Brussels, Brussels, Republic of Belgium \\ Email: "goupoly@yahoo.fr
}

Received April 21 $1^{\text {st }}, 2012$; revised May $19^{\text {th }}, 2012$; accepted June $4^{\text {th }}, 2012$

\begin{abstract}
This study aims at assessing the modifications of renal parameters with 13 female players of the same Benin team-amateur Division 1, during two consecutive handball games played 26 hours apart. The players are divided into two groups: starters $(\mathrm{ST}: \mathrm{N}=7$ ) and nonstarters (NS: $\mathrm{N}=6$ ). The estimated glomerular filtration rate (eGFR) with Cockcroft-Gault and MDRD formulas, the fractional excretion of sodium $(\mathrm{FeNa})$, the plasma haemoglobin $(\mathrm{Hb})$ and albumin $(\mathrm{Alb})$ were assayed at rest and at the end of each game. At the end of the first game, only eGFR decreased significantly by at least $16.30 \%(p<0.05)$ in ST only. At the end of the second game, the average reductions of eGFR are significant in both the ST and NS groups $(p<0.05)$, but they are less important than those recorded at the end of the first $(p>0.05)$. FeNa varied in no group, neither after the first game, nor after the second $(p>0.05)$. But a cumulative reduction is observed between the values before the first and those recorded at the end of the second game in both ST and NS groups. The status of the players (ST or NS) did not influence the results. Two games of handball played 26 hours apart in the sub-Saharan environment of Cotonou caused in girls, a transitory decrease in eGFR without a cumulative effect. FeNa decreased too, but with a cumulative effect which indicates large sodium retention.
\end{abstract}

Keywords: Renal Function; Handball; Girls; Hot Environment; Benin

\section{Introduction}

The transition from resting to physical exercise may cause benign or pathological modifications in different organs particularly in the kidneys, because of the redistribution of the cardiac output to active muscles (Goffin \& Nielsens, 2006). This induces a decrease in renal blood flow, in accordance with the exercise intensity, and consequently a transitory deterioration in the renal hemodynamic as well as a stimulation of the electrolytes and proteins excretion (Poortmans, 1995). Works on the interaction between exercise and kidney are scarce and most of them were undertaken in developed countries with moderate climate (Lippi, Banfi, Salvagno, Franchini, \& Guidi, 2008b; Poortmans \& Ouchinsky, 2006). The majority of studies related to renal function, undertaken in Africa and particularly in developing countries, were about the epidemiological aspects of renal affections (Naicker, 2009; Gnionsahe, Lagou, \& Tia, 2007). Moreover, most of the data about renal adaptations to exercise, relate to individual sports practitioners, especially the males (Afshar, Sanavi, \& Jalali Nadooshan, 2009; Lippi et al.,

\footnotetext{
"Corresponding author.
}

2008a), so that information on the game sports and the sportswomen is scarce. One of the recent studies on renal adaptations to exercise carried out in African tropical environment concerns the effects of a basketball game on the renal parameters (Gouthon et al., 2009). In spite of the transitory character of renal dysfunction highlighted by the authors of the latter study, it is critical to know the mode of adaptation of the kidneys to physical burden resulting from a series of games played in a competition period. That is more especially needed in game sports, particularly in the field of African handball, in which the competitions are organized as grouped tournaments, with short resting periods between games.

Handball is a game sport characterized by a playing intensity which increases the heart rate to $85 \%$ of its maximum value and a high level of physical commitment indicated by frequent attacker-defender duels, as well as very short and explosive actions, like ball throws (Buchheit, 2005). All these characteristics suggest that a handball game exerts strong constraints on the whole functions which contribute to homeostasis, particularly on renal function, especially when the game takes place in hot and humid sub-Saharan environment like that of Cotonou in 
the South of the Republic of Benin.

This environment is indeed characterized in the daytime by an ambient temperature which varies between $29^{\circ} \mathrm{C}$ and $34^{\circ} \mathrm{C}$ and a relative humidity between $70 \%$ and $90 \%$ (Encarta, 2008), likely to induce high levels of dehydration and damage to the sportsmen health.

In such a context, the players often participate in two or three consecutive games approximately 24 hours apart, being thus exposed to a physical and thermal stress. The possible renal dysfunctions recorded after a handball game on the most solicited players that are starters, are currently ignored, as well as the effects of a second game played without a sufficient rest.

This study consequently aims at comparing in starters and nonstarters of the same team, the modifications of the renal parameters during a series of two handball games, played in the sub-Saharan environment of the Republic of Benin.

\section{Material and Methods}

\section{Study Sample}

This is a casual comparative study, carried out in December 2009 in Cotonou (Republic of Benin, West Africa), with female handball players involved in the preliminary stages of the national championship of the amateur-Division 1. The non-probabilistic study sample is composed of 13 senior voluntary players out of among the 14 available at the beginning of the tournament (age: $25.6 \pm 5.7$ years; weight: $56.4 \pm 6.0 \mathrm{~kg}$; height: $165.6 \pm 5.3 \mathrm{~cm}$; BMI: $\left.20.5 \pm 2.0 \mathrm{~kg} / \mathrm{m}^{2}\right)$. The starters' group ( $\mathrm{ST}: \mathrm{N}=7$ ) is composed of players entering on the playground at the first half-time, during each of the first two games of the tournament, whereas the nonstarters' group (NS: N=6) is formed of a while other girl players or non-players of the two games.

\section{Criteria of Inclusion}

The criteria of inclusion in the study sample are as follows: be a black player; be a resident in Benin at least a year ago because of feeding habits; be 18 years old or more, i.e. being a player of the senior team retained for the study; give one's written and informed consent to take part in the study.

\section{Criteria of Non-Inclusion}

Any player under anti-hypertensive, anti-malarial treatment or anti-inflammatory drug or under any other treatment likely to influence the renal parameters was excluded. There was one under non-steroidal anti-inflammatory drug (NSAID). So she was excluded from the study.

\section{Measurements and Study Variables}

The distance covered during the games was measured using Manuel Y-2028 (Géonaute Decathlon, China) podometers. EDTA tubes (for blood hemoglobin and hematocrit) and dry tubes (for creatinine, albumin, and electrolytes) are used per player, to take $10 \mathrm{~mL}$ of blood sample. Dry tubes were used to take 10 $\mathrm{mL}$ of urine per player for creatinine and electrolytes assays. Graduated tubes (10 to $1500 \mathrm{~mL}$ ) were used to measure the quantity of water drunk by the players at the end of each game. A spectrophotometer RT-9200 (Rayto, Germany) was used for assaying blood and urinary creatinine, as well as plasma albumin. Sodium and potassium were assayed by photometry with electrons of reference, with an Electrolyte Analyser ISE 4500 (Sfri, France). Blood hemoglobin and the hematocrit rate were determined using an automated Counter M-Series (Medonic, Sweden).

The estimated glomerular filtration rate (eGFR) was calculated using plasma creatinine in the formula of Cockcroft-Gault (C-G) (Cockcroft \& Gault, 1976) normalized and that of MDRD (Levey et al., 2006). The glomerular function is considered altered for any value of eGFR lower than $90 \mathrm{~mL} / \mathrm{min} / 1.73 \mathrm{~m}^{2}$. The fractional excretion of sodium

$$
=100 \times \frac{(\text { urine sodium }[\mathrm{mmol} / \mathrm{L}] \times \text { plasma creatinine }[\mathrm{mg} / \mathrm{dL}])}{(\text { plasma sodium }[\mathrm{mmol} / \mathrm{L}] \times \text { urine creatinine }[\mathrm{mg} / \mathrm{dL}])}
$$

was also calculated (Carvounis, Nisar \& Guro-Razuman, 2002). For these authors and in this study, a FeNa resting value lower than $1 \%$ suggests an acute functional renal insufficiency and a value higher than $2 \%$ indicates an acute tubular necrosis, two functional acute renal failures.

The plasma hemoglobin, creatinine and albumin were determined by traditional techniques of clinical biology, i.e. respecttively with automated Counter, by the colorimetrical technique (Jaffé, 1886) and that of final point (Pinnell \& Northam, 1978). Plasma hemoglobin $(\mathrm{Hb})$ and albumin (Alb) respectively lower than $12 \mathrm{~g} / 100 \mathrm{~mL}$ and higher than $52 \mathrm{~g} / \mathrm{L}$ (Janssens, 2009) were considered abnormal, i.e. jointly associated with anemia and dehydration.

At the end of each game and during the recovery, the variation of plasma volume $(\Delta \mathrm{PV})$ was calculated using the following formula:

$$
\begin{aligned}
\Delta \mathrm{PV}(\%)= & 100 \times \text { Hbbefore } / \text { Hbafter } \\
& \times\left\{\frac{[1-(\text { Hematocritafter } / 100)]}{[1-(\text { Hematocritbefore } / 100)]}\right\}-100
\end{aligned}
$$

In this formula, Hbbefore and Hematocritbefore represent respectively plasma resting (before the game) $\mathrm{Hb}$ and Hematocrit, then Hbafter and Hematocritafter, those measured at the end of the game (Dill \& Costill, 1974).

\section{Study Design}

The day before the first game, all the 13 players (starters and nonstarters) filled out a questionnaire addressing their sports practice, personal history of cardiovascular and renal diseases and their menstrual status. On the first day, measurements were taken before the warm up of the players registered for the game. After a 20 min-warm up, each game was played in full time, i.e. 30 min $\times 2$ with a 15 min-break (International Handball Federation, 2010). Just at the end of the game, the second measurements were taken and the total quantity of water drunk by the girls was assessed. The second game was played by the same girls 26 hours later, according to the tournament schedule. The same operations and procedures of measurements were taken again with the second game. Figure 1 shows the chronological order of blood sampling and urine taking throughout the study.

The blood samples were taken from an antecubital vein of the left elbow of the players and assayed as well as the urine taken, within two hours, after storage in a refrigerator. The podometers were programmed and read by evaluators accustomed to their use. During and after the games, the girls were 


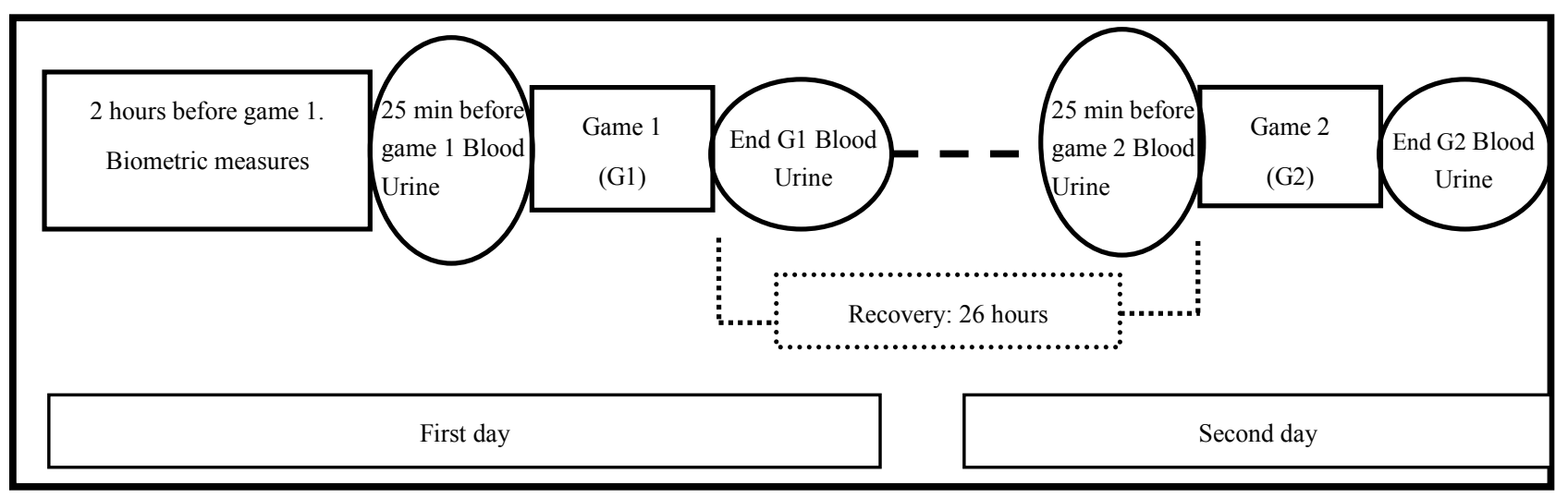

G1: first game; G2: second game.

Figure 1.

Schematic representation of the study design.

authorized to drink ad libitum water containing (in $\mathrm{mg} / \mathrm{L}$ ) $\mathrm{Na}^{+}=$ $5.8 ; \mathrm{K}^{+}=0.4 ; \mathrm{Cl}^{-}=10 ; \mathrm{Ca}^{++}=3.1 ; \mathrm{Mg}^{++}=1.5 ;$ Bicarbonates $=$ 9.8; Sulfates $=1.2$; Nitrates $<3$. The last training session of the girls took place 48 hours before the first game and each time, the last meal was consumed at least four hours before the beginning of the game.

\section{Ethical Considerations}

A week before the games, all the players were informed of the objective, the procedure of the study, the data confidentiality, the safety dispositions, as well as incurred possible risks, before giving their written informed consent. The study was approved by the Sports Science Council (named CSS/STAPS) of the University of Abomey-Calavi, acting as the ethic committee.

\section{Statistical Analysis}

The data were processed with the software Statistica (Stat Soft Inc., Version 8.0). Descriptive statistics: mean values (M), standard deviation (S) were calculated for each variable studied. The normal distribution of the variables was checked, using the test of Kolmogorov-Smirnov. A two-factor analysis of variance (Anova) was undertaken to check the interaction (Time of measurement $x$ Status). A one factor Friedman Anova was used to test the time of measurement effect. In case of significant Anova, the multiple comparison tests: the post hoc test of Tukey, the test of Wilcoxon or the U of Mann Withney test was applied, depending on the case. The level of significance of all statistical tests was set at $p<0.05$.

\section{Results}

\section{Biometric Characteristics, Menstrual Status of the Players and Game Data}

The players involved in the study are $25.6 \pm 5.7$ years old (19 - 37 years), trained on average $5 \pm 1$ hours per week, for $10 \pm 5$ years. Whatever the biometric variable considered, no significant difference $(p>0.05)$ appears between the ST and NS (Table 1). None of the players has a history of arterial hypertension and/or renal disease. Three girls out of 13, among whom one ST were in menstrual phase (first to second days), four players out of 13 among whom three ST were in follicular phase $\left(6^{\text {th }}\right.$ to $14^{\text {th }}$ days) and six girls out of 13 among whom three ST players were in premenstrual or secretory phase $\left(17^{\text {th }}\right.$ to $23^{\text {rd }}$ days $)$.

The games were played in-door under a temperature and a relative humidity varying respectively between $32^{\circ} \mathrm{C}$ and $35^{\circ} \mathrm{C}$, then $62 \%$ and $63 \%$. The experimental team won the first game by 26 goals against 24, but they lost the second one, by 18 goals against 21 . In the ST group, each player covered on average $3603 \pm 2411 \mathrm{~m}$ during the first game, $3598 \pm 1108 \mathrm{~m}$ during the second one, and drank firstly on average $923 \pm 393$ $\mathrm{mL}$ and $909 \pm 343 \mathrm{~mL}$ during the second game. In the NS group, each player covered on average $1342 \pm 945 \mathrm{~m}$ during the first game, $929 \pm 899 \mathrm{~m}$ for the second, and then drank on average $574 \pm 370 \mathrm{~mL}$ during the first game and $476 \pm 520 \mathrm{~mL}$ for the second one. In the ST and NS groups, respective reductions of $8.9 \% \pm 8.1 \%$ and $12.8 \% \pm 6.2 \%$ of the PV were recorded at the end of the first game, against $0.8 \pm 6.1 \%$ and $4.9 \pm 6.6 \%$ at the end of the second one. A reduction of $10.0 \% \pm 9.8 \%$ of the PV was recorded in the ST group $(p>0.05)$ against $8.2 \% \pm 8.1 \%$ in NS $(p<0.05)$. At the end of each game, significant differences appear between the ST and NS groups with regard to the distance covered $(p=0.038$ for the first game and $p=0.0042$ for the second one). The NS players drank significantly less than the ST ones, during the second game $(p=0.045)$.

At rest, none of the players has the plasma Alb higher than $52 \mathrm{~g} / \mathrm{L}$ and there was not a significant difference between the ST and NS players $(p>0.05)$.

\section{Evolution of the Renal Parameters during the Games}

In the ST group, the eGFR according to C-G and MDRD decreased respectively by $16.30 \%(p=0.017)$ and by $18.87 \%(p=$ $0.017)$ at the end of the first game, then increased by $18.30 \%$ ( $p$ $=0.017)$ and by $21.69 \%(p=0.017) 26$ hours later, without reaching the resting value. It then decreased by $14.92 \%(p=$ $0.017)$ for $C-G$ and by $16.97 \%(p=0.017)$ for MDRD at the end of the second game (Figures 2 and 3). In the NS group, the eGFR did not vary at the end of the first game $(p>0.05)$ but it increased 26 hours later (C-G: 13.74\%, $p=0.043$; MDRD: $15.87 \%, p=0.043)$ before decreasing at the end of the second one (C-G: $11.99 \%, p=0.027$; MDRD: $13.69 \%, p=0.027$ ).

At the end of the first game, the variations of eGFR recorded in the ST group are higher than those observed in NS (C-G, $p=$ 0.045 ; MDRD, $p=0.045$ ). When the two games are taken together, 


\section{B. A. TONON ET AL.}

Table 1.

Biometric characteristics of the handball female players studied $(\mathrm{N}=13)$.

\begin{tabular}{lcccccc}
\hline & Age (years) & Height $(\mathrm{m})$ & Weight $(\mathrm{kg})$ & BSA $\left(\mathrm{m}^{2}\right)$ & BMI $\left(\mathrm{kg} / \mathrm{m}^{2}\right)$ & RHR $(\mathrm{bpm})$ \\
\hline ST (N = 7) & $25.8 \pm 6.4$ & $1.6 \pm 0.6$ & $56.3 \pm 6.0$ & $1.6 \pm 0.1$ & $20.6 \pm 2.0$ & $76 \pm 13$ \\
NS (N = 6) & $25.5 \pm 5.0$ & $1.6 \pm 0.4$ & $56.5 \pm 6.6$ & $1.6 \pm 0.1$ & $20.4 \pm 2.2$ & $74 \pm 10$ \\
\hline
\end{tabular}

Values in the cases are means $(\mathrm{M}) \pm$ standard deviations (SD); ST: starters; NS: nonstarters; N: sample size; BMI: body mass index; BSA: body surface area; RHR: resting heart rate.

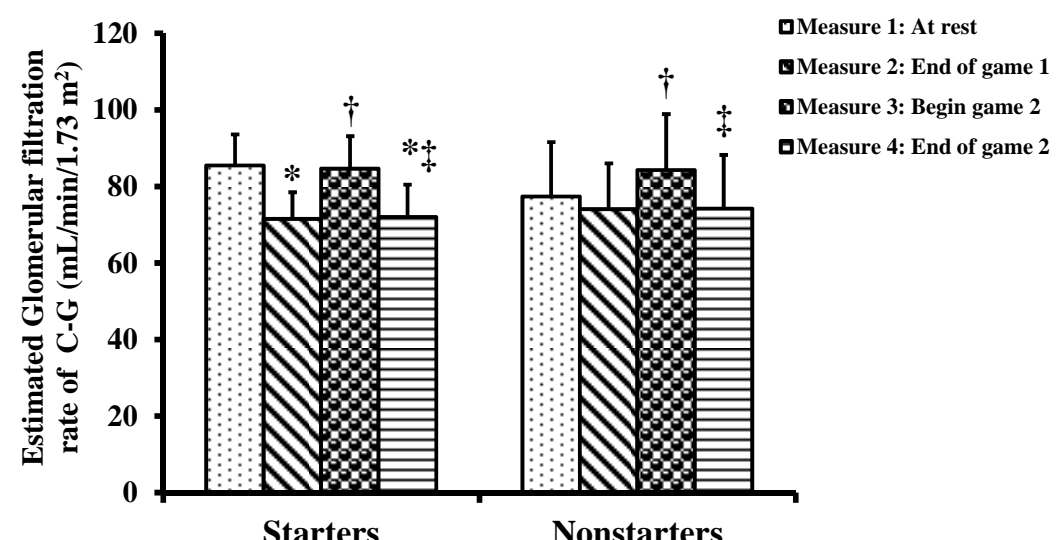

The bars on the histogram represent standard deviation (SD); C-G: Cockcroft and Gault (1976); *difference with Measure 1, significant at $p<0.05$; ${ }^{\dagger}$ difference with Measure 2, significant at $p<0.05$; ${ }^{*}$ difference with Measure 3, significant at $p<0.05$.

Figure 2.

eGFR with the Cockcroft and Gault formula (1976) standardized, in the studied players during the two games. Interaction (time of measurement $\times$ status), $p<0.0001$; Anova for time of measurement, $p=0.0021$ (Starters), $p=0.064$ (Nonstarters).

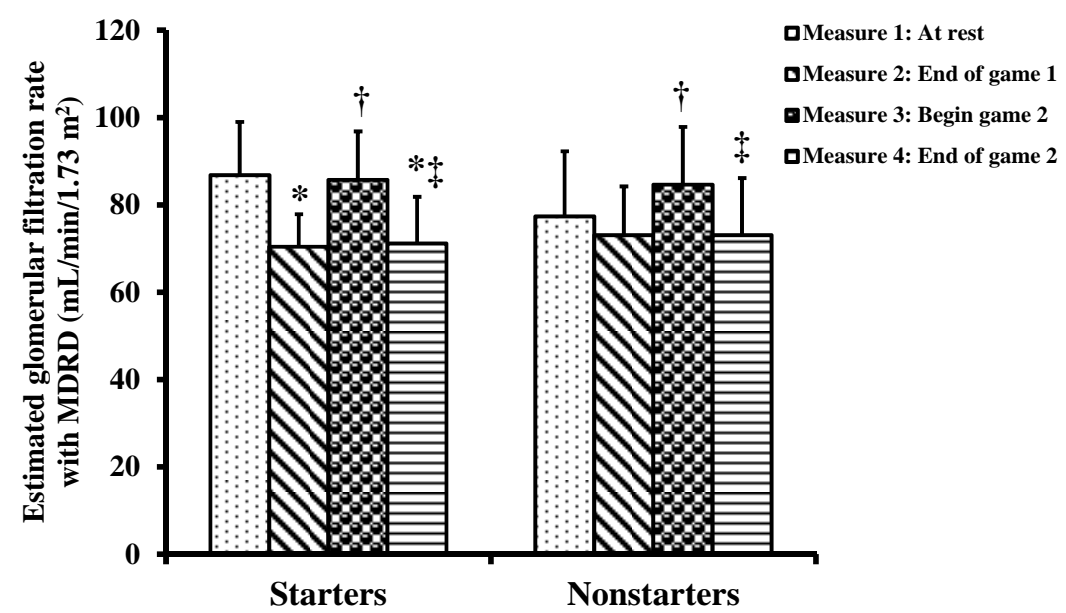

The bars on the histogram represent standard deviation (SD); MDRD: Modification of Diet in Renal Disease equation of Levey et al. (2006); ${ }^{*}$ difference with Measure 1 , significant at $p<0.05$; ${ }^{\dagger}$ difference with Measure 2, significant at $p<0.05 ;{ }^{\ddagger}$ difference with Measure 3, significant at $p<0.05$.

Figure 3.

eGFR with MDRD equation (Levey et al., 2006) in the studied players during the two games. Interaction (time of measurement $\times$ status), $p<0.0001$; Anova for time of measurement, $p=$ 0.0021 (Starters), $p=0.064$ (Nonstarters).

the modifications of eGFR recorded do not present a significant difference compared to those recorded at the end of the first game, in the ST group ( $p=0.86$ for $\mathrm{C}-\mathrm{G}$ and MDRD) as well as in NS ( $p=0.71$ for C-G and MDRD). The eGFR standard deviations appear more significant in the NS group than in ST, irrespective of the formula used (Figures 2 and 3).
The FeNa did not vary significantly in the two groups (ST and NS) neither at the end of the first game, nor at the end of the second one (Figure 4). During the 26 hours which followed the end of the first game, FeNa decreased in the two groups (ST: $85.43 \%, p=0.026$; NS: $88.88 \%, p=0.015)$. At the end of the second game, the reductions of $\mathrm{FeNa}$ recorded in the two groups 


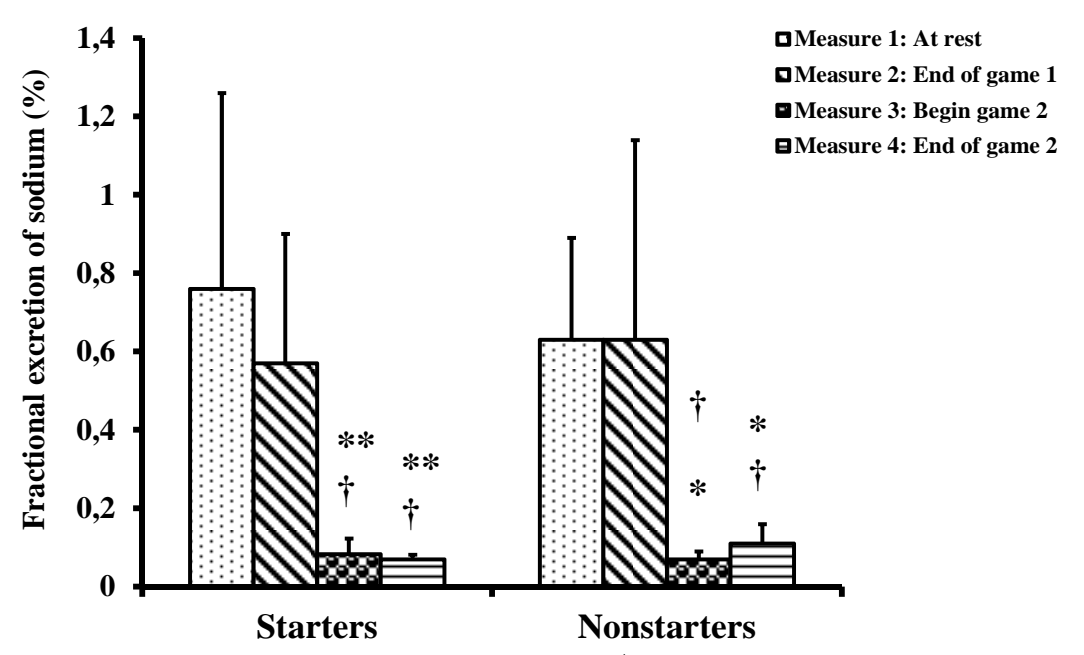

The bars on the histogram represent standard deviation (SD); ${ }^{*}$ difference with Measure 1 , significant at $p<$ $0.05 ;{ }^{* *}$ difference with Measure 1 , significant at $p<0.01 ;$ difference with Measure 2 , significant at $p<$ 0.05 .

Figure 4.

$\mathrm{FeNa}$ in the studied players during the two games. Interaction (time of measurement $\times$ status), $p<0.0001$; Anova for time of measurement, $p<0.001$ (Starters), $p<0.01$ (Nonstarters).

are more significant than those obtained at the end of the first one (ST: $0.68 \pm 0.49 \%$ versus $0.18 \pm 0.21 \%, p=0.017$ ) and (NS: $0.51 \pm 0.24 \%$ versus $0.00005 \pm 0.27 \% p=0.027$ ), without presenting however significant difference between them $(p>$ $0.05)$. At rest, the standard deviations are more significant in the NS group than in ST, whereas the opposite phenomenon is observed at the end of the games.

\section{Discussion}

This study produced innovative experimental results, primarily in relation to renal function of the African populations involved in physical activities in sub-Saharan environment. Our investigation was carried out in the competition period, during the preliminary stages of handball championship (Division 1) in Benin, with the team of amateur senior-players who took up the fourth position for qualification to the final phase.

The majority of the girls (77\%) were in post-menstrual period, i.e. in follicular or secretory phase. The first phase which induces an increase in the plasma estrogen concentration can favor water retention and deeply alter the sodium and potassium excretion (Pitkin, Reynolds, Williams \& Hargis, 1978). The increased plasma progesterone concentration often observed during the secretory phase impacts on the aldosterone, which can culminate in a high sodium excretion (Szmuilowicz et al., 2006). It does not seem to be the case in our series, since a reduction of the fractional sodium excretion was recorded, during the 26 hour-recovery period.

The temperature and the relative humidity recorded during the games suggest that the girls made an effort under a high thermal stress likely to disturb their central cardiovascular adaptation (heart) as well as the peripheral one (muscles, skin). In fact, during a physical exercise in a hot and humid environment like that of this study, the thermal stress can induce an increase in core temperature, tiredness and a risk of accident, resulting from the dehydration caused by sweat losses (Koulmann, Banzet \& Bigard, 2003).

The high standard deviations observed on the distance covered by the starters, account for the heterogeneity of the group regarding their participation in the game, since real play times are unequal. They can justify the high variations observed with regard to the eGFR according to the two formulas used.

The absence of significant difference in the variation of the plasma volume between the two groups (starters and nonstarters), from the beginning of the first game to the end of the second $(-10 \%$ and $-8 \%, p=0.77)$, though the starters drank during the second game more than the nonstarters, is probably in relation to the hydration level of the players during the games. This hydration level can be regarded as less compensatory in hot and humid environment, when compared with the recommendations in the literature (Casa et al., 2000; American College of Sports Medicine, 1996). The volume of water drunk on average by the girls before $(250 \mathrm{~mL})$ and after each game, though partially in conformity with the recommendations in starters, did not contribute to avoid the decrease of plasma volume in these players.

The weak rate of plasma hemoglobin $(\mathrm{Hb}<12 \mathrm{~g} / 100 \mathrm{~mL})$ noted in all the girls of the two groups of our series, could be associated with a nutritional deficiency and/or malaria or intestinal parasites. As a matter of fact, anemia in black African subjects usually results from combination between nutritional deficiency, iron losses due to intestinal parasites, hemolysis caused by malaria infections and genetic factors (Nussenblatt \& Semba, 2002). The menstrual blood loss and the worsening of the renal function constitute other factors which may induce an abnormal decrease of plasma hemoglobin in these post-pubescent girls. Some authors have also reported a high prevalence of anemia in their series of female basketball players in Benin (Gouthon et al., 2009) and in white Italian young fertile non-professional female athletes (Di Santolo, Stel, Banfi, Gonano, \& Cauci, 2008). One can notice that, some reports did not reveal abnormal plasma $\mathrm{Hb}$ in female cyclists (Schumacher, Pottgiesser, Ahlgrim, Ruthardt, Dickhuth, \& Roecker, 2008; Sims, Rehrer, Bell, \& Cotter, 2007). Since the values before the preparation of the competition are not available, the assumption of pseudo-anemia could not be completely isolated when explaining the high prevalence of weak plasma $\mathrm{Hb}$ in this study. 
On one hand, the reference values of plasma albumin (32 to $58 \mathrm{~g} / \mathrm{L}$ ) proposed by Bigot et al. (1996) for the non-sporting Benin population and those suggested by Janssens (2009) for Europeans population ( 35 to $52 \mathrm{~g} / \mathrm{L}$ ), help to assert that no player was dehydrated at the beginning of this study. On the other hand, if one refers to the usual values (from 33 to $45 \mathrm{~g} / \mathrm{L}$ ) reported for the general female population in Europe (Burtis, Ashwood \& Bruns, 2005), or to the mean value (41 g/L) found in Africa (Adéwoye \& Fawibe, 1978), 87.5\% of the female players involved in this study should be regarded as dehydrated at rest. This divergence in the available data suggests the need for establishing in short term, the specific standards for the sporting population in the Republic of Benin, even in sub-Saharan Africa.

The disparities in the renal responses recorded during the games are to be associated to the inequality in the real playing time of the starters, since at rest a relative homogeneity was observed, drawing aside thereby the influence of their sporting practice.

The main cause of the reduction of eGFR after each game would be in relation to the decrease in the renal blood flow in favor of the active muscles (Goffin \& Nielsens, 2006). The reductions of these parameters recorded at the end of the first game are however transitory, since 26 hours later, the tendencies were reversed. These phenomena observed in the present study and reported by different authors (Gouthon et al., 2009; Lippi et al., 2008b) are well-known. In fact, the pre-cited authors recorded a transitory decrease in the clearance of creatinine at the end of a basketball game, while the latters observed a reduction of eGFR at the end of a semi-marathon of $21 \mathrm{~km}$. In another study (Lippi et al., 2008a), it has been recorded an increase in eGFR after a cycling test, whereas another author (Poortmans, Jourdain, Heyters \& Reardon, 1990) did not observe any significant modification of the values of this parameter after a rowing test. The divergence between our results and those of the latter authors could be mainly associated to hydration status or to differences in exercise intensity in the studies. It appeared that the second handball game did not exert a cumulative effect on the eGFR in the players of this study. The abnormally reduced sample size, as well as the 26 hour-recovery between the two games could influence negatively the results of statistical tests and renal responses.

The standard deviations, less significant in the starters' group compared to that of the nonstarters show a less inter-individual variation and probably indicate a relative homogeneity of the starters' group, with regard to the renal response to the effort.

The reduction of FeNa in both the starters and nonstarters' groups at the end of the two games, could be attached to the decrease of plasma volume (Carvounis et al., 2002) resulting from the sudation caused by the high thermal stress in the sports hall, as well as the tubular reabsorption stimulated jointly by an increased production of vasopressin and aldosterone, both induced by intense exercise (Sims et al., 2007).

The variations of FeNa recorded could also be associated with an inadequate hydration in the players of the two groups during the 26 hour-recovery period. This phenomenon has been already reported in sportsmen (Yeargin et al., 2010). The effect of vasopressin and aldosterone lasts from 12 to 48 hours after the exercise (Brooks \& Mercier, 1994). Unlike the observations relating to the two parameters of eGFR, a cumulative effect of the two games was observed on FeNa. The values lower than $1 \%$ recorded suggests the occurrence of a transitory renal func- tional insufficiency in these female handball players. FeNa is indeed generally lower than $1 \%$ in subjects suffering from acute glomerulonephritis, hepato-renal syndrome and any cause of renal functional insufficiency like severe congestive cardiac insufficiency, incomplete and acute obstruction of the urinary tracts or dehydration (Fesler, 2007). The decrease in FeNa, some hours after the effort, is in conformity with the literature data (Gerth et al., 2002; Irving, Noakes \& van Zyl-Smit, 1989).

The results of this study support the idea according to which a series of two handball games played in hot and humid environment by the girls of Benin elite does not deteriorate to a significant degree the glomerular function. Then the data collected help to think that the competitive continuation of handball practice can be recommended to these players, since they are subjected to a balanced diet. This intake dietary may help to normalize their plasma hemoglobin values and to ensure hydro-mineral balance after one, even two games played 24 to 36 hours apart, as it is often the case in the official competitions in Africa.

\section{Study Limits}

Since the players' dietary including intake water may affect the glomerular filtration rate (eGFR) and the fractional excretion of sodium $(\mathrm{FeNa})$, we would like to assess it in this study, but we could not do it accurately, because they use to take their meals individually at home or in restaurants at the edge of roads. Although these data will be very useful to explain the results, data collected in such conditions may not be reliable. The conclusions of the study are also limited to only women, since only female players took part of it. Their team was indeed the only one playing at the handball Division 1 level in Porto-Novo, the town where the study was carried out.

\section{Conclusion}

The group of the studied female players evoked a state of benign anemia. The assumption according to which playing a second handball game in the hot and humid environment of the sport hall of Cotonou, only 26 hours after the first, causes an additional deterioration of the renal glomerular function, is not confirmed. The only renal parameter for which a cumulative effect was highlighted is the FeNa. It seems useful to carry on this study with a more significant series of games (four to six), in order to validate the absence of more significant disturbance of renal function. It is indeed an issue of keeping safely the current formulae of Benin handball championship (Division 1) organization, arranged in two phases in forms of grouped tournaments: the preliminary with five games and the final with at least three games per team in five days.

\section{Acknowledgements}

The authors are indebted to the managers of the Centre of Muscular and Cardiovascular Maintenance VITAFORME of Porto-Novo (Republic of Benin), for their technical support during data processing and analysis, as well as the final preparation of the manuscript.

\section{REFERENCES}

Adéwoye, H. O., \& Fawibe, J. F. (1978). Serum albumin level in an 
urban Nigerian population. British Journal of Nutrition, 40, 439-442. doi:10.1079/BJN19780145

Afshar, R., Sanavi, S., \& Jalali Nadooshan, M. R. (2009). Urinary sodium and potassium excretion following karate competitions. Iran Journal of Kidney Disease, 3, 86-88.

American College of Sports Medicine (1996). Position stand on exercise and fluid replacement. Medicine and Science in Sports and Exercise, 28, 1-7.

"Bénin” Encyclopédie Microsoft ${ }^{\circledR}$ Encarta $^{\circledR}$ (2008). URL (Last checked 10 January 2010). http://fr.encarta.msn.com

Bigot, A., Akpona, S., Attolou, V., Avodé, G., Djrolo, F., Houngbè, F., Fatoke, M., \& Zohoun, I. (1996). Valeurs de référence de 11 protéines sériques dans une population apparemment en bonne santé. Journal de la Société de Biologie Clinique (Bénin), 3, 45-48.

Brooks, G. A., \& Mercier, J. (1994). Balance of carbohydrate and lipid utilization during exercise: The "crossover' concept. Journal of Applied Physiology, 76, 2253-2261.

Buchheit, M. (2005). Connaissances adultes. Le 30-15 Intermittent Fitness Test: Illustration de la programmation du travail de la puissance maximale aérobie à partir d'un test de terrain approprié. Approches du Handball, 88, 36-46.

Burtis, C. A., Ashwood, E. R., \& Bruns, D. E. (2005). Tietz textbook of clinical chemistry and molecular diagnostics $\left(4^{\text {th }}\right.$ ed. $)$, Paris: Elsevier Saunders.

Carvounis, C. P., Nisar, S., \& Guro-Razuman, S. (2002). Significance of the fractional excretion of urea in the differential diagnosis of acute renal failure. Kidney International, 62, 2223-2229. doi:10.1046/j.1523-1755.2002.00683.x

Casa, D. J., Armstrong, L. E., Hillman, S. A., Montain, S. J., Reiff, R. V., Rich, B. S. E., Roberts, W. O., \& Stone, J. A. (2000). National athletic trainers' association position statement: Fluid replacement for athletes. Journal of Athletic Training, 35, 212-224.

Cockcroft, D. W., \& Gault, H. M. (1976). Prediction of creatinine clearance from serum creatinine. Nephron, 16, 31-41. doi:10.1046/j.1523-1755.2002.00683.x

Dill, D. B., \& Costill, D. L. (1974). Calculation of percentage changes in volumes of blood, plasma, and red cells in dehydration. Journal of Applied Physiology, 37, 247-248.

Di Santolo, M., Stel, G., Banfi, G., Gonano, F., \& Cauci, S. (2008). Anemia and iron status in young fertile non-professional female athletes. European Journal of Applied Physiology, 102, 703-709. doi:10.1007/s00421-007-0647-9

International Handball Federation (IHF) (2010). International handball federation rules. Basel: IHF.

Fesler, P., \& Mimran, A. (2007). Ionogramme urinaire de 24 heures: Comment l'interpréter? Journal de Néphrologie-Cardiologie, 18.

Gerth, J., Ott, U., Fünfstück, R., Bartsch, R., Keil, E., Schubert, K., Hübscher, J., Scheucht, S., \& Stein, G. (2002). The effect of prolonged physical exercise on renal function, electrolyte balance and muscle cell breakdown. Clinical Nephrology, 57, 425-431.

Gnionsahe, D. A., Lagou, D. A., \& Tia, W. M. (2007). Prevalence of acquired cystic disease in Black Africans on hemodialysis in West Africa. Saudian Journal of Kidney Disease and Transplantation, 18, 114-116.

Goffin, E., \& Nielsens, H. (2006). Peut-on pratiquer un sport lorsqu'on est insuffisant rénal chronique, dialysé ou transplanté? AIRGFrance: Information Medicale 2006. URL (Last checked 1 July 2009). http://www.airg-france.org

Gouthon, P., Tonon, B. A., Ouendo, E.-M., Falola, J.-M., Agboton, B., Dansou, H. P. \& Poortmans, J. R. (2009). Evolution des paramètres associés à la fonction rénale après un match de basketball en milieu africain subsaharien. Science \& Sports, 24, 293-301. doi:10.1016/j.scispo.2009.03.004

Irving, R. A., Noakes, T. D., \& van Zyl-Smit, R. (1989). Metabolic and renal changes in two athletes during a world 24 hours relay record performance. British Journal of Sports Medicine, 23, 227-232. doi:10.1136/bjsm.23.4.227

Jaffé, N. (1886). Ueber den neiderschlag, welchen pikrinsaeure in normalen harn erzeugt un über eine neue reaktion des kretinins. Zeitschrift für Physiologische Chemie, 10, 391-400.

Janssens, G. (2009). Répertoire d'analyses de biologie clinique [on line]. 3rd Edition, Brussels. URL (Last checked 22 December 2010). www.ulb-ibc.be/Repertoire_IBC_2009_2.pdf

Koulmann, N., Banzet, S., \& Bigard, A. X. (2003). L'activité physique à la chaleur: De la physiologie aux recommandations d'apport hydrique. Medecine Tropicale, 63, 617-626.

Levey A. S, Coresh J., Greene T., Stevens L. A., Zhang Y. L., Hendriksen S., Kusek, J. W., \& Van Lente, F. (2006). Chronic kidney disease epidemiology collaboration. Using standardized serum creatinine values in the modification of diet in renal disease study equation for estimating glomerular filtration rate. Annals of Internal Medicine, $145,247-254$.

Lippi, G., Schena, F., Salvagno, G. L., Tarperi, C., Montagnana, M., Gelati, M., Banfi, G., \& Guidi, G. C. (2008a). Acute variation of estimated glomerular filtration rate following a half-marathon run. International Journal of Sports Medicine, 29, 948-951.

Lippi, G., Banfi, G., Salvagno, G. L., Franchini, M., \& Guidi, G. C. (2008b). Glomerular filtration rate in endurance athletes. Clinical Journal of Sport Medicine, 18, 286-288. doi:10.1097/JSM.0b013e31817049c5

Naicker, S. (2009). End-stage renal disease in sub-Saharan Africa. Ethnicity Disease, 19, 13-15.

Nussenblatt, V., \& Semba, R. D. (2002). Micronutrient, malnutrition and the pathogenesis of malarial anemia. Acta Tropica, 82, 321-337. doi:10.1016/S0001-706X(02)00049-9

Pinnell, A. E., \& Northam, B. E. (1978). New automated dye-binding method for serum albumin determination with bromocresol purple. Clinical Chemistry, 24, 808-806.

Pitkin, R. M., Reynolds, W. A., Williams, G. A., \& Hargis, G. K. (1978). Calcium regulating hormones during the menstrual cycle. Journal of Clinical Endocrinology and Metabolism, 47, 626-632. doi: $10.1210 /$ jcem-47-3-626

Poortmans, J.-R., \& Ouchinsky, M. (2006). Glomerular filtration rate and albumin excretion after maximal exercise in aging sedentary and active men. The Journals of Gerontology Series A: Biological Sciences and Medical Sciences, 61, 1181-1185. doi:10.1093/gerona/61.11.1181

Poortmans, J.-R. (1995). La réponse rénale à l'exercice chez le sujet sain et pathologique. Nephrology, 16, 317-324.

Poortmans, J.-R., Jourdain, M., Heyters, C., \& Reardon, F. D. (1990). Postexercise proteinuria in rowers. Canadian Journal of Sport Science, $15,126-130$.

Schumacher, Y. O., Pottgiesser, T., Ahlgrim, C., Ruthardt, S., Dickhuth, H.-H., \& Roecker, K. (2008). Haemoglobin mass in cyclists during stage racing. International Journal of Sports Medicine, 29, 372-378. doi:10.1093/gerona/61.11.1181

Sims, S. T., Rehrer, N. J., Bell, M. L., \& Cotter, J. D. (2007). Preexercise sodium loading aids fluid balance and endurance for women exercising in the heat. Journal of Applied Physiology, 103, 534-541. doi:10.1152/japplphysiol.01203.2006

Szmuilowicz, E. D., Adler, G. K., Williams, J. S., Green, D. E., Yao, T. M., Hopkins, P. N., \& Seely, E. W. (2006). Rlationship between aldosterone and progesterone in the human menstrual cycle. Journal of Clinical Endocrinology and Metabolism, 91, 3981-3987. doi:10.1210/jc.2006-1154

Yeargin, S. W., Casa, D. J., Judelson, D. A., McDermott, B. P., Ganio, M. S., Lee E. C, Lopez, R. M., Stearns, R. L., Anderson, J. M., Armstrong, L. E., Kraemer, W. J., \& Maresh, C. M. (2010). Thermoregulatory responses and hydration practices in heat-acclimatized adolescents during preseason high school football. Journal of Athletic Training, 45, 136-146. doi:10.4085/1062-6050-45.2.136 